\title{
Gestão da cadeia de suprimentos integrada à tecnologia da informação*
}

\author{
Gleim Dias de Souza** \\ Maria do Socorro M. V. de Carvalho*** \\ Manuel Alejandro Martínez Liboreiro****
}

\section{Introdução}

\section{Formulação do problema}

Os hospitais são certamente a forma mais complexa de organização humana que nos propomos a administrar.

Sua complexidade inicia-se pela natureza de sua missão. Tecnicamente, um hospital é um prestador de serviços, mas é grande a distância entre salvar vidas e as outras atividades do setor de serviços.

Por conseguinte, o seu supply chain management (SCM) tem que ser desenvolvido para agregar valores acima da média em relação às outras modalidades de prestação de serviço.

\footnotetext{
* Trabalho de conclusão de curso apresentado ao Curso MBA Executivo Internacional FGV Business and Management for International Professionals - UCI. Pós-graduação lato sensu, nível de especialização. Programa FGV Management.

** Médico especialista em radiologia e diagnóstico por imagem, MBA em estratégia empresarial (FGV), certificado Business and Management for International Professionals (Universidade da Califórnia, Irvine), MBA em gestão empresarial (FIA/USP). Endereço: SQS 102, bloco G, ap. 203 - CEP 70330-070, Brasília, DF, Brasil. E-mail: gleimdias@uol.com.br.

*** Administradora, mestre em administração pública, professora da Ebape/FGV, superintendente da FGV em Brasília. Endereço: SHIS QI 3, cj. 9, casa 7, Lago Sul - Brasília, DF, Brasil. E-mail: socorro@bsb.fgv.br.

$* * * *$ Contador (UNCPBA, Argentina), MBA em administração financeira e mercado de capitais (FGV), certificado Business and Management for International Professionals (Universidade da Califórnia, Irvine). Endereço: SQSW 102, bloco L, ap. 208, Sudoeste - Brasília, DF, Brasil. E-mail: alejandro.martinez@br.transx.com.br.
} 
A criticidade da maioria dos medicamentos e materiais geralmente é alta, não sendo permitida a demora na entrega ou mesmo a falta de uma gama de medicamentos que são imprescindíveis para os tratamentos realizados.

A análise das ferramentas de TI disponíveis para a formulação de supply chain management, permitindo uma integração maior com os fornecedores quando necessário, maior transparência, melhores resultados e satisfação dos clientes internos e externos é a chave para alcançar o sucesso pretendido.

Com a maior comunicabilidade proporcionada pelas ferramentas de TI, aumenta a chance de reduzir a desconfiança característica do relacionamento comercial, podendo-se com isso estabelecer um novo paradigma de relacionamento permitindo o estabelecimento do SCM.

Por outro lado, é de suma importância também determinar a eficiência da força do comprador na negociação com os fornecedores, baseados nas cinco forças competitivas de Porter.

As ferramentas de TI determinam uma grande vantagem competitiva na medida em que aumentam a eficiência e a eficácia do SCM.

O leilão reverso pela internet impõe-se como ferramenta de primeira escolha no caso de compras com características de informação estruturada, ou seja, que permitem uma parametrização adequada, pela sua facilidade de implantação, transparência e resultados obtidos, sendo utilizada como parte de uma estratégia que culminará com a implantação plena do SCM.

A utilidade do leilão reverso é primeiramente aumentar a base de fornecedores e, com um conselho gestor, podermos avaliar e escolher com quais fornecedores iremos desenvolver o SCM. Também aumenta a força do comprador num primeiro momento, determinando uma significativa queda dos preços antes do início das negociações. Por último, ter uma plataforma que permita agilidade em compras para as exceções e também, caso tenhamos que rescindir o contrato de SCM, para a troca de fornecedores.

\section{Objetivo geral}

Realizar análise das principais ferramentas de TI que determinam melhoria na criação e manutenção do supply chain management eficiente.

\section{Objetivos específicos}

- Analisar a teoria na área de TI voltada para supply chain management.

口 Analisar a aplicabilidade dessas ferramentas.

- Demonstrar estudo de caso da aplicabilidade de leilão reverso em ambiente hospitalar com suas vantagens e dificuldades. 


\section{Justificativa}

Numa análise do metamercado hospitalar, podemos ter idéia do desafio que é estabelecer rotinas para o desenvolvimento de um supply chain management eficiente nessa área.

Figura 1

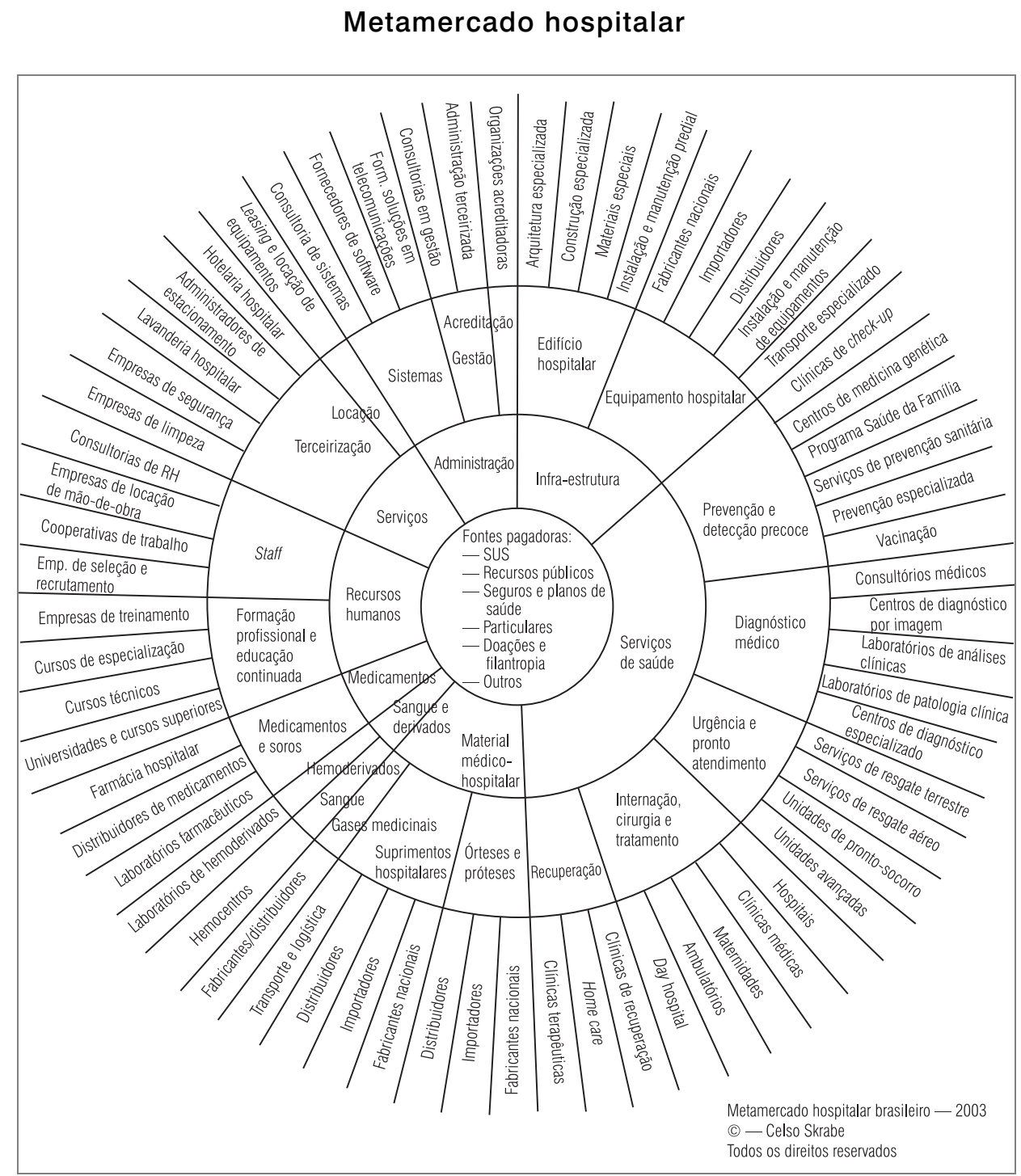

Rap Rio de Janeiro 40(4):699-729, Jul./Ago. 2006 
A cultura relacional entre fornecedores e hospitais em muitos casos é baseada na desconfiança e controle; em vários casos justificada pela ausência de confiabilidade por parte da rede hospitalar no cumprimento de prazos, qualidade e preços.

As ferramentas da tecnologia da informação impõem-se como fortes aliadas para o sucesso dessa missão.

Com o ferramental de TI, podemos ter planos de ressuprimentos feitos com maior rapidez, compras em tempo curto com preços e prazos melhores e a mesma ou melhor qualidade.

Vantagens competitivas podem ser obtidas por meio do suporte da tecnologia e sistemas de informação, de modo que amplie a capacidade de uma organização em lidar com clientes, fornecedores, produtos e serviços substitutos, e novos competidores no mercado. A análise pode ser baseada no modelo das forças competitivas de Porter (1991).

A rapidez da evolução é uma forte característica da tecnologia da informação. Em poucos anos foram desenvolvidas várias ferramentas que, isoladas ou em conjunto, auxiliam o supply chain management eficiente.

\section{Metodologia}

Para este artigo, foram feitas uma pesquisa exploratória e uma pesquisa bibliográfica com uma aplicação prática de ferramentas da tecnologia da informação voltadas para o supply chain management hospitalar que, na prática, em nada difere de qualquer outro.

A fundamentação teórica foi realizada com base em exaustiva pesquisa bibliográfica, utilizando livros, artigos, entrevistas, revistas e sites disponíveis sobre o assunto abordado.

Segundo Vergara (1998:46):

Pesquisa bibliográfica é o estudo sistematizado desenvolvido com base em material publicado em livros, revistas, jornais, redes eletrônicas, isto é, material acessível ao público em geral. Fornece instrumental analítico para qualquer outro tipo de pesquisa, mas também pode esgotar-se em si mesma.

Este artigo avalia os resultados econômico-financeiros auferidos pela análise horizontal comparativa de um ano de implantação da ferramenta de TI (leilão reverso) com o mesmo período de tempo anterior à implantação.

RAP Rio de Janeiro 40(4):699-729, Jul./Ago. 2006 
A ferramenta foi implantada de forma pioneira na região, em rede hospitalar localizada no Centro-Oeste do Brasil, como parte de uma estratégia de criação de SCM, ou seja, um estudo de caso.

Segundo Vergara (1998:47):

Estudo de caso é o circunscrito a uma ou poucas unidades, entendidas essas como uma pessoa, uma família, um produto, uma empresa, um órgão público, uma comunidade ou mesmo um país. Tem caráter de profundidade e detalhamento. Pode ou não ser realizado no campo.

\section{Definição e histórico do supply chain management e ferramentas de TI}

Compreende-se como cadeia de suprimentos, um conjunto de instalações dispersas geograficamente interagindo entre si. Como exemplos dessas instalações tem-se: fornecedores de matéria-prima, plantas produtivas, centros de distribuição, varejistas, estoque em trânsito, produtos intermediários e produtos acabados entre as instalações (Yin, 1991).

A cadeia de suprimentos é um subconjunto da cadeia de valor, a qual é focada em agregar valor a um serviço ou a um produto físico, enquanto a cadeia de suprimentos é preocupada principalmente com a produção, distribuição e vendas de produtos físicos (Simchi-Levi et al., 2000).

Na gestão da cadeia de suprimentos o foco é a integração de cada componente, com maximização da eficiência determinando maior satisfação do cliente e conseqüentemente o aumento do market share.

De acordo com Nazário (1999):

Maximizar a utilização de ativos, maximizar a utilização da atual cadeia de suprimentos incluindo a tecnologia da informação, temos nos anos 1970 preocupações voltadas à eficiência do back office ou objetivos operacionais. Como exemplos podemos citar sistemas de automação (controle de processo etc.), ou automação empresarial (sistemas computadorizados de contabilidade etc.).

Nos anos 1980, eficiência no front office ou eficiência estratégica foi a preocupação. Nessa época, sistemas como reservas de passagens aéreas funcionaram como uma forte vantagem competitiva. Hoje, a gestão da cadeia de suprimentos é um bom exemplo onde ambos, objetivos e utilização de tecnologias da informação, contêm aspectos de eficiência operacional e estratégica. 
De acordo com a literatura dominante, pode-se conceituar canal de distribuição como a estrutura das unidades organizacionais internas e externas, dos agentes, representantes, atacadistas e varejistas por meio dos quais uma commodity, produto ou serviço é comercializado (figura 2).

Figura 2

Fluxo simplificado de comercialização

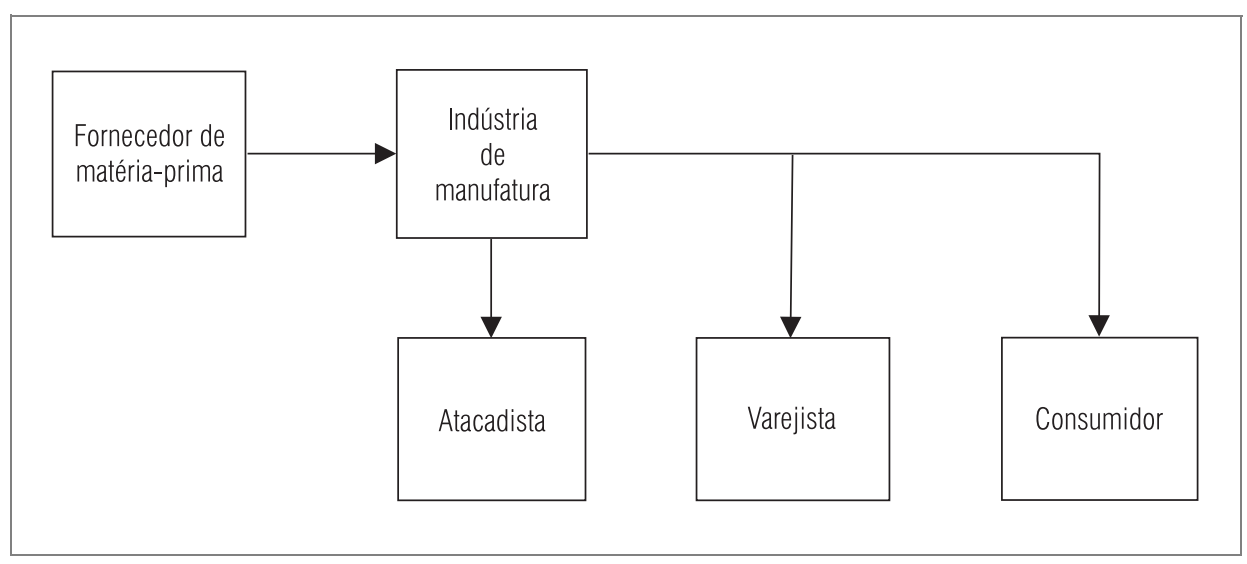

A complexidade e multiplicidade de relacionamentos dentro da cadeia de comercialização têm que ser equacionadas para um mesmo objetivo, que é a missão da empresa. Essa missão do comprador tem que estar equacionada com a missão do fornecedor, suas práticas de mercado e padrão ético.

O gerenciamento eficaz do SCM (figura 2) é baseado no relacionamento direto dos que trabalham diariamente, pois a idéia é reduzir os lead-times e estoques ao mínimo necessário.

Conforme Chopra e Meindl (2001),

informação é essencial para tomar boas decisões de gerenciamento da cadeia de suprimentos porque ela proporciona o conhecimento do escopo global necessário para tomar boas decisões. A tecnologia da informação proporciona as ferramentas para reunir essas informações e analisá-las objetivando tomar as melhores decisões sobre a cadeia de suprimentos.

Strati (1995) confirma esta proposição argumentando que as organizações estão deixando de ser sistemas relativamente fechados para transforma- 
rem-se em sistemas cada vez mais abertos. As fronteiras estão se tornando cada vez mais permeáveis, e em muitos casos difíceis de se identificar. A separação entre empresa e o ambiente passa a ser delimitada por uma tênue linha divisória, incerta e mutável. Muitas vezes, a empresa se confunde com o ambiente, misturando fornecedores e clientes. Fica difícil saber onde termina a cooperação e começa a concorrência.

Lambert, Cooper e Pagh (1998) entendem que o SCM pode ser considerado uma tentativa de estabelecer um corte transversal das fronteiras organizacionais visando viabilizar a gestão de processos entre corporações. Os próprios autores advertem que "gerenciar uma cadeia de suprimentos é uma tarefa desafiadora e que é muito mais fácil escrever definições sobre esses processos do que implementá-los".

Conforme argumentou Ballou (1993), o conceito básico de logística, do qual evoluíram vários outros é "colocar o produto certo, na hora certa, no local certo e ao menor custo possível". Apesar de ser um conceito genérico, reflete de forma clara a abrangência e o objetivo da logística.

Segundo o Council of Logistics Management (CLM),

Logística é a parcela do processo da cadeia de suprimentos que planeja, implanta e controla, de forma eficiente e eficaz, o fluxo e o fluxo reverso e a estocagem de materiais, serviços, e as informações correlacionadas, entre o ponto de origem e o ponto de consumo, de forma a atender as necessidades dos clientes.

Segundo Lambert (1993), "o conceito de gerenciamento integrado de logística se refere à administração das várias atividades como um sistema integrado".

Entretanto, o conceito de custo atrelado à integração das atividades logísticas é o de custo total conforme Bowersox.

Christopher (1999) também amplia o conceito, considerando que

a logística empresarial abrange as áreas que tratam diretamente com o fluxo de beneficiamento das matérias-primas em produtos acabados, tanto no aspecto interno de uma organização empresarial quanto no aspecto externo, envolvendo todos os fornecedores de matérias-primas e partes que compõem um produto, até o ponto de ocorrência da demanda deste produto pelo consumidor final.

É interessante observar a definição dada pelo Council of Logistics Management para o SCM: 


\begin{abstract}
Gerenciamento da cadeia de suprimentos é a coordenação estratégica e sistêmica das funções de negócio tradicionais bem como as ações táticas que perpassam essas funções numa companhia e através de negócios dentro da cadeia logística com o propósito de aprimorar a performance de longo prazo das companhias individualmente e da cadeia de suprimentos como um todo.
\end{abstract}

Para Fleury, Wanke e Figueiredo (2000) a integração externa, outra das dimensões de excelência logística, significa desenvolver relacionamentos cooperativos com os diversos participantes da cadeia de suprimentos, baseados na confiança, capacitação técnica e troca de informações. A integração externa permite eliminar duplicidades, reduzir custos, acelerar o aprendizado e customizar serviços.

Lambert (1993) considera o gerenciamento da cadeia de suprimentos "a integração dos processos-chave de negócios desde o usuário final até os fornecedores originais que provêem produtos, serviços e informações que agregam valor para os consumidores e demais interessados no negócio".

As empresas transnacionais que tiverem a coragem de adotar a visão de planejamento das cadeias de abastecimento globais poderão obter economias de abrangência, escala e velocidade, fatores-chave para a liderança mundial. Os acontecimentos mundiais estão forçando as empresas a considerar os méritos de processos de planejamento de tal abrangência.

Para avaliação do estágio de uma organização, segundo modelo desenvolvido por Bowersox e colaboradores (1992), o nível de desenvolvimento da estrutura logística de uma empresa pode ser analisado a partir de três dimensões básicas: formalização da função logística, monitoramento de desempenho e adoção de tecnologia.

\title{
Decisóes e horizontes de planejamento da gestão da cadeia de suprimentos
}

Hax e Golovin (1978) agruparam um grande número de decisões sobre gestão de manufatura, que afetam as organizações em três níveis hierárquicos: estratégico, tático e operacional.

Decisões estratégicas dizem respeito a alianças, investimentos, aquisições de recursos, desenvolvimento de produto, cujo foco está no longo prazo. O horizonte de planejamento é longo, de um a cinco anos.

Decisões táticas referem-se à produção agregada, planejamento agregado de distribuição e alocação de recursos, cujo foco está na minimização do 
custo total e maximização da receita líquida no médio prazo. O horizonte de planejamento é médio, de um mês a um ano.

Decisões operacionais tratam da produção detalhada e do planejamento da distribuição, cujo foco está na minimização do custo local baseado nas decisões dos níveis mais altos, estratégico e tático no curto prazo. O horizonte de planejamento é curto, de um dia a um mês.

\section{Ferramentas de TI utilizadas em supply chain management}

Bowersox e Closs apontam três razões para a necessidade de informações rápidas, em tempo real e com alto grau de precisão para uma gestão eficiente da logística e da cadeia de suprimentos.

Primeiro, clientes entendem que informações do andamento de uma ordem, disponibilidade de produtos, programação da entrega e dados do faturamento são elementos fundamentais do serviço ao cliente. Segundo, com a meta de redução do estoque em toda a cadeia de suprimentos, os executivos percebem que, com informações adequadas, eles podem, efetivamente, reduzir estoques e necessidades de recursos humanos. Especialmente, o planejamento de necessidades sendo feito usando informações mais recentes, permite reduzir estoques através da minimização das incertezas da demanda. Em terceiro, a disponibilidade de informações aumenta a flexibilidade com respeito a saber, quanto, quando e onde os recursos podem ser utilizados para obtenção de vantagem estratégica.

Anupindi e colaboradores (1999) mostram a abrangência e os níveis de funcionalidade dos sistemas de informação utilizados no SCM. Como abrangência eles consideram que a TI deve prover soluções adequadas aos três níveis de gestão: estratégico, tático e operacional.

Segundo Wanke (2004),

Diversos clientes e fornecedores quiseram redesenhar seu fluxo de produtos, operações de produção e distribuição através de um maior compartilhamento de informações. Essas iniciativas são comumente chamadas de "programas de resposta rápida - PPRS". Existem várias modalidades de PPR, cada qual atendendo por uma sigla diferente: ECR, CRP, VMI, CPRF, QR etc.

Todos os sistemas podem ser analisados num continuum. De um lado estão os estoques e no outro as informações. O compartilhamento das informações possibilita aos fornecedores um planejamento e tomada de decisão 
mais eficiente. Na consignação o fornecedor é o proprietário dos estoques e o responsável pela sua gestão até que eles sejam utilizados pelo cliente.

No compartilhamento de informações, o fornecedor pode utilizá-las de duas formas: para previsão e programação de políticas de gestão de estoques e para a operacionalização dos princípios de melhoria contínua de processos.

Quick response (QR). Os fornecedores recebem os dados coletados nos pontos-de-venda do cliente e utilizam essa informação para sincronizar suas operações de produção e seus estoques com as venda reais dos clientes.

Continuous replenishment (CR). Os fornecedores recebem os dados do ponto-de-venda para preparar carregamentos em intervalos regulares e assegurar a flutuação do estoque no cliente entre determinados níveis máximo e mínimo. Destaca-se que esses níveis de estoque podem variar em função de padrões sazonais de demanda, de promoções e de mudança no gosto do consumidor.

Efficient consumer response (ECR). Fornecedores e clientes cooperam em cinco áreas principais: compartilhamento de informações em tempo real, gerenciamento de categorias, reposição contínua, custeio baseado em atividades e padronização.

A reposição contínua permite o gerenciamento just-in-time. Os produtos não são mais armazenados em centros de distribuição e sim movimentados rapidamente por instalações de cross-docking.

O compartilhamento de informações asseguraria a seqüência mais apropriada para a montagem dos carregamentos, bem como o melhor mix de produtos.

O gerenciamento de categorias consiste no agrupamento de produtos com as mesmas características mercadológicas, a fim de coordenar a definição de metas de vendas e de políticas de preços, evitando a utilização intensiva de estratégias promocionais.

A padronização buscaria estabelecer normas e rotinas para a operacionalização do fluxo de produtos e informações, pela uniformização dos meios de transporte, dos procedimentos para liberação e recepção de veículos e a troca eletrônica de dados.

$\mathrm{O}$ custeio baseado em atividades permitiria quantificar as melhorias operacionais obtidas com o ECR.

Collaborative planing, forecasting and replenishment (CPFR). O CPFR constitui uma extensão do CRP/ECR no qual fabricantes e varejistas compartilham sistemas e o processo de previsão de vendas. O objetivo principal é identificar qual empresa gera previsões de vendas mais precisas para um determinado 
SKU (stock keeping unit), numa determinada região geográfica, num determinado horizonte de planejamento.

Vendor managed inventory (VMI). O VMI tende a ocorrer quando o poder de barganha dos fornecedores é maior que o dos seus clientes. A idéia é que, ao gerenciar os estoques na cadeia, os fornecedores sejam capazes de programar melhor suas operações motivados por elevados custos de oportunidade de manter estoques.

No entanto, a consignação pode ocorrer no VMI, caso o poder de barganha do cliente seja maior que o do fornecedor ou como forma de convencimento dos clientes.

A consignação pode ocorrer caso o poder de barganha do cliente seja maior que o do fornecedor ou como forma de convencimento dos clientes.

Na consignação, as chances de conflito na relação cliente-fornecedor tendem a ser minimizadas quando o cliente sinaliza com uma maior previsibilidade de consumo do produto consignado, quando os custos de oportunidade de manter estoques são conhecidos e quando existem expectativas de nível de serviço bem definidas.

A rotina do $\mathrm{VMI}$ envolve:

- rever a posição em estoque de cada SKU em cada loja da cadeia varejista;

- checar a disponibilidade atual do SKU em estoque no fabricante, em função de ordens de produção liberada anteriormente e defasada do tempo da resposta;

- projetar as necessidades líquidas de estoque por SKU por loja da cadeia varejista;

- checar se as necessidades líquidas projetadas caem abaixo dos níveis de estoque de segurança. No VMI são projetadas as necessidades líquidas futuras até a próxima revisão e não simplesmente geradas previsões de vendas.

Just-in-time (JIT II). O JIT II consistiria na extensão lógica do regime de produção JIT para fora da empresa. No JIT II o fornecedor disponibilizaria um funcionário para trabalhar no seu cliente. Esse funcionário é conhecido como in-plant e tomaria decisões relacionadas à programação de produção e aquisição de insumos. O in-plant substitui as funções de comprador e do planejador no cliente e a função do vendedor no fornecedor. 


\begin{tabular}{|c|c|c|c|c|}
\hline \multicolumn{5}{|c|}{$\begin{array}{l}\text { Quadro } 1 \\
\text { de sistemas de SCM }\end{array}$} \\
\hline Programa & $\begin{array}{l}\text { Quem decide } \\
\text { a reposição }\end{array}$ & $\begin{array}{l}\text { Como decide a } \\
\text { reposição }\end{array}$ & $\begin{array}{l}\text { Propriedade dos } \\
\text { estoques }\end{array}$ & $\begin{array}{l}\text { Como o fornecedor } \\
\text { utiliza os dados da } \\
\text { demanda }\end{array}$ \\
\hline$Q R$ & Cliente & $\begin{array}{l}\text { Previsão de vendas e } \\
\text { independente do } \\
\text { fornecedor }\end{array}$ & Cliente & $\begin{array}{l}\text { Aprimorar previsão de } \\
\text { vendas e sincronizar as } \\
\text { operações }\end{array}$ \\
\hline CRP & Fornecedor & $\begin{array}{l}\text { Com base na posição } \\
\text { de estoque. } 0 \text { nível de } \\
\text { reposição é decidido } \\
\text { em conjunto }\end{array}$ & Fornecedor/cliente & $\begin{array}{l}\text { Atualizar posição de } \\
\text { estoques e modificar nível } \\
\text { de reposição em conjunto } \\
\text { com varejo }\end{array}$ \\
\hline ECR & Fornecedor & $\begin{array}{l}\text { Com base na posição } \\
\text { de estoque. } 0 \text { nível de } \\
\text { reposição é decidido } \\
\text { em conjunto }\end{array}$ & Fornecedor/cliente & $\begin{array}{l}\text { Atualizar posição de } \\
\text { estoques e modificar nível } \\
\text { de reposição em conjunto } \\
\text { com varejo }\end{array}$ \\
\hline CPFR & Fornecedor & $\begin{array}{l}\text { Com base na posição } \\
\text { de estoque. } 0 \text { nível de } \\
\text { reposição é decidido } \\
\text { em conjunto }\end{array}$ & Fornecedor/cliente & $\begin{array}{l}\text { Aprimorar previsão de } \\
\text { vendas e sincronizar as } \\
\text { operações com a } \\
\text { participação do cliente }\end{array}$ \\
\hline VMI & Fornecedor & $\begin{array}{l}\text { Com base na necessidade } \\
\text { líquida projetada }\end{array}$ & $\begin{array}{l}\text { Fornecedor/cliente } \\
\text { ou consignado }\end{array}$ & $\begin{array}{l}\text { Gerar previsão de vendas e } \\
\text { projetar necessidade líquida }\end{array}$ \\
\hline JIT II & In-plant & $\begin{array}{l}\text { De acordo com o sistema } \\
\text { de suporte à decisão do } \\
\text { cliente }\end{array}$ & Fornecedor/cliente & $\begin{array}{l}\text { Aprimorar previsão de } \\
\text { vendas e sincronizar as } \\
\text { operações }\end{array}$ \\
\hline
\end{tabular}

\section{Avaliação de desempenho em cadeias de suprimentos}

Várias abordagens sugerem que o foco de avaliação de desempenho em cadeias de suprimentos são os processos.

Na definição dos processos, não há concordância de nomenclatura entre todos os trabalhos, mas todos tratam como processos as etapas do fluxo que ocorrem em uma empresa, desde o planejamento da aquisição até a entrega dos produtos ao cliente ou o retorno.

Vários autores propõem que todas as empresas mensurem os indicadores para a cadeia e realizem benchmarking, para facilitar a busca de melhori- 
as no contexto da cadeia de suprimentos (Stewart, 1995; SCC, 2002; Aravechia e Pires, 2000).

Outros também propõem que os indicadores sejam integrados entre os membros de uma cadeia, para que todos tenham a mesma percepção do que é importante e das metas de desempenho a alcançar (Bowersox e Closs, 1996).

Por outro lado, Gunasekaran, Patel e Tirtiroglu (2001) propõem indicadores referentes a parcerias, envolvimento com os fornecedores, valor percebido pelo produto entregue e outros indicadores de avaliação de aspectos além das fronteiras da empresa, o que mostra preocupação com a troca de informações e com maior proximidade dos fornecedores e clientes, mas também considerando apenas os objetivos de uma empresa.

O trabalho de Cravens, Piercy e Cravens (2000) é específico para uma parceria entre empresas, mas, mesmo nesse caso, a avaliação proposta seria feita por apenas uma empresa.

Além disso, nessa abordagem, os autores propõem a utilização do balanced scorecard, mas não discutem sua aplicação - apenas usam sua estrutura para abrigar os indicadores.

O BSC emprestou apenas as quatro perspectivas ao modelo de Cravens, Piercy e Cravens (2000), já que a única menção a ele ocorre na utilização das perspectivas para "alojar" os indicadores.

Dreyer (2000) afirma que os stakeholders, incluindo fornecedores e clientes, devem ser envolvidos na definição dos indicadores de desempenho, mas não mostra como isso ocorreria e como eles seriam envolvidos nessa mensuração, já que ele afirma que os indicadores seriam identificados em torno dos processos-chave da cadeia que ocorrem internamente à empresa (obtenção, aquisição, processamento e distribuição). No final do trabalho, Dreyer (2000) lembra que os indicadores devem manter um objetivo maior em mente: satisfazer as necessidades do cliente final.

O trabalho de Miranda (1996) apresenta uma proposta para avaliação de desempenho das montadoras, na indústria automobilística, diferenciada para cada componente e tipo de relação. Em função do grande número de componentes necessários para produzir um veículo e da tecnologia envolvida, a prática de confiar a terceiros a produção de grande parte dos componentes necessários para montar um veículo e transferir tecnologia a esses parceiros já está bastante experimentada nas montadoras. Porém, mesmo nessa situação, percebe-se pelo trabalho de Miranda que as relações ainda são baseadas primeiramente em preço. Mesmo nessa indústria há muito ainda a ser feito para que as empresas busquem a melhoria das cadeias de suprimentos e não de empresas isoladamente. 
Aravechia e Pires (2000) propõem a utilização dos indicadores de desempenho da proposta de Beamon (1999), mas a enriquecem com a sugestão do uso de um diagrama em forma de radar, que pode ajudar as empresas de uma cadeia a visualizarem o seu desempenho e o dos demais membros, visualizando também áreas de aprimoramento.

Holmberg (2000) buscou analisar a implicação da falta de pensamento sistêmico nos problemas que ocorrem na avaliação de desempenho da cadeia de suprimentos. O autor aborda importantes aspectos que devem ser considerados para evitar os problemas identificados, e utiliza exemplos extraídos de uma pesquisa que ele realizou.

Stank e colaboradores (2001), a partir de uma investigação empírica, fornecem importantes subsídios para a implementação de um modelo de avaliação de desempenho em uma cadeia. Os autores relatam aspectos que devem ser observados para que haja integração entre as empresas, identificando empiricamente o que as empresas acreditam ser importante para integrar a avaliação de desempenho.

Brewer e Speh (2001) e Lambert e Pohlen (2001) possuem um foco mais amplo, com maior preocupação com a cadeia de suprimentos efetivamente, abordando a necessidade de esforços conjuntos entre seus membros, para a melhoria do desempenho da cadeia inteira.

E Lambert e Pohlen (2001) criticam os indicadores ditos da cadeia, utilizados pelas empresas, como o giro de estoques, por exemplo, e propõem uma abordagem em que são analisadas as relações de uma empresa com seus fornecedores e clientes, considerando-se pares de organizações. Os indicadores propostos são o EVA (economic value added), demonstrativos de resultado de cada relação e indicadores não-financeiros para cada um dos processos de negócio da cadeia. Os autores crêem que pela análise das relações entre as empresas, nos processos de negócio, feita pelos membros de uma cadeia, poderão ser identificadas oportunidades de melhoria que beneficiarão todas as empresas e o cliente final.

No trabalho de Lambert e Pohlen (2001), pouca ênfase é dada à definição de indicadores não-financeiros, com maior discussão sobre como construir os demonstrativos de resultado das relações. Os autores também reconhecem que o modelo pode ser modificado, depois de ser testado em um caso real.

A proposta de Narasimhan e Kim (2002) não foi incluída entre as abordagens pesquisadas nesta seção, já que não se tratava de um trabalho direcionado ao tema, apesar de conter os indicadores relacionados no quadro 2.

Percebe-se que as propostas contemplam indicadores a serem mensurados tanto para os parceiros a jusante como para aqueles a montante de uma empresa, e outros específicos, alguns para as etapas a jusante, e outros para as etapas a montante de uma empresa. 


\begin{tabular}{|c|c|c|c|c|c|c|c|c|}
\hline Quad & 0 -resumo & comparative & do & $\begin{array}{r}\text { Qu } \\
\text { ntes e depoi }\end{array}$ & $\begin{array}{l}\text { Iadro } 2 \\
\text { is de executado }\end{array}$ & o procureme & onsolidado & \\
\hline Antes & & Depois & & Projetado & Geren & ciamento de risc & Efeitos & \\
\hline Descrição & Índices & Índices & $\%$ & Índices & Tipo de risco & $\begin{array}{l}\text { Minimização } \\
\text { do risco }\end{array}$ & Problema & Resolução \\
\hline & & & & & Macro & & $\begin{array}{l}\text { Parametrização } \\
\text { dos fornecedores }\end{array}$ & $x$ \\
\hline $\begin{array}{l}\text { Taxas efetivas } \\
\text { (materiais e } \\
\text { medicamentos) }\end{array}$ & & & & & $\begin{array}{l}\text { País (1) } \\
\text { Mercado }\end{array}$ & & $\begin{array}{l}\text { Registro dos } \\
\text { fornecedores }\end{array}$ & $x$ \\
\hline Gestão & & & & & & & $\begin{array}{l}\text { Logística de } \\
\text { entrega }\end{array}$ & $x$ \\
\hline $\begin{array}{l}\text { Valor comprado por } \\
\text { fornecedores }\end{array}$ & $382.612,68$ & $3.165 .569,39$ & 1,05 & $3.308 .020,01$ & Risco financeiro & & $\begin{array}{l}\text { Itens errados - } \\
\text { "X-fornecedores" }\end{array}$ & $x$ \\
\hline $\begin{array}{l}\text { Diferença entre pedidos } \\
\text { e entregas }\end{array}$ & $2.676,00$ & $1.871,00$ & - & - & 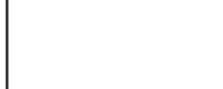 & & & \\
\hline Liquidações no período & $998.770,11$ & $938.526,61$ & 1,05 & $980.760,31$ & Risco cambial (3) & Hedge & $\begin{array}{l}\text { Boa aceitação do } \\
\text { pessoal }\end{array}$ & $x$ \\
\hline NFs erradas & 623,00 & $1.245,00$ & 0,05 & 62,25 & $\begin{array}{l}\text { Risco de variação } \\
\text { dos juros (2) }\end{array}$ & Hedge & & \\
\hline $\begin{array}{l}\mathrm{N} \text { - } \text { de itens corretos/ } \\
\text { totais }\end{array}$ & 0,60 & 0,12 & 4,00 & 0,48 & $\begin{array}{l}\text { Risco do } \\
\text { investimento } \\
(1+2+3+4)\end{array}$ & $\begin{array}{l}\text { Treinamento e } \\
\text { hedge }\end{array}$ & & \\
\hline
\end{tabular}




\begin{tabular}{|c|c|c|c|c|c|c|c|c|}
\hline \multicolumn{2}{|c|}{ Antes } & \multirow{2}{*}{$\begin{array}{l}\text { Depois } \\
\text { Índices }\end{array}$} & \multicolumn{2}{|c|}{ Projetado } & \multicolumn{2}{|c|}{ Gerenciamento de riscc } & \multicolumn{2}{|c|}{ Efeitos } \\
\hline Descrição & Índices & & $\%$ & Índices & Tipo de risco & $\begin{array}{c}\text { Minimização } \\
\text { do risco }\end{array}$ & Problema & Resolução \\
\hline Empregadores & 5 & 2 & & - & $\begin{array}{l}\text { Segurança dos } \\
\text { aplicativos }\end{array}$ & $\begin{array}{l}\text { Testes de alta } \\
\text { tecnologia }\end{array}$ & & \\
\hline & & & & & $\begin{array}{l}\text { Precisão dos } \\
\text { sistemas }\end{array}$ & $\begin{array}{l}\text { Testes de alta } \\
\text { tecnologia }\end{array}$ & & \\
\hline Fornecedores & & & & & $\begin{array}{l}\text { Queda dos } \\
\text { sistemas e } \\
\text { interrupções }\end{array}$ & $\begin{array}{l}\text { Testes de alta } \\
\text { tecnologia }\end{array}$ & & \\
\hline & & & & & $\begin{array}{l}\text { Disponibilidade } \\
\text { do sistema }\end{array}$ & $\begin{array}{l}\text { Testes de alta } \\
\text { tecnologia }\end{array}$ & & \\
\hline Locais & 15 & 15 & & - & & & & \\
\hline Nacionais & 0 & 85 & & - & & & & \\
\hline $\begin{array}{l}\text { Índices econômico- } \\
\text { financeiros }\end{array}$ & & & & & & & & \\
\hline Ativos & $108.501,52$ & $118.648,95$ & & $105.335,30$ & & & & \\
\hline Estoques & $1.844,51$ & $1.708,77$ & & $1.196,14$ & & & & \\
\hline Passivos correntes & $106.546,17$ & $70.693,77$ & & $73.095,13$ & & & & \\
\hline Fornecedores & $5.550,80$ & $3.540,30$ & & $3.186,27$ & & & & \\
\hline Vendas & $63.057,62$ & $35.527,11$ & & $47.783,96$ & & & & \\
\hline
\end{tabular}




\section{E-procurement}

Hábitos de compra ineficientes e independentes, processos de negócio redundantes e ausência de fontes estratégicas são sintomas de práticas deficientes de procurement ou obtenção. Estratégias empresariais eficientes de obtenção integram o fluxo de trabalho de uma companhia com uma infra-estrutura tecnológica consistente. $\mathrm{O}$ crescimento da internet trading exchanges (ITE) representa um dos desenvolvimentos mais instigantes nesses últimos anos.

A obtenção está evoluindo da função de suporte para uma valiosa arma no arsenal competitivo de uma corporação. As empresas buscam soluções para o alto custo de obtenção e o tempo prolongado do ciclo de pedido, enquanto garantem que a entrega de materiais ou serviços aconteça sem problemas.

Não é uma revolução tecnológica que vem ocorrendo, mas sim uma revolução de negócios facilitada pela tecnologia.

Os cinco desafios-"chave" do procurement são: reduzir custo e tempos do ciclo de processamento do pedido; fornecer a toda empresa acesso às capacidades do e-procurement; autorizar requisições por meio de auto-serviço do funcionário; buscar integração de software de obtenção com sistemas de atividades de retaguarda da empresa e elevar a função de obtenção a uma posição de importância estratégica dentro da organização.

O mercado de e-procurement ainda é jovem. Porém os modelos de negócios exigidos para servir a esse mercado estão evoluindo rapidamente. Na era préinternet, grandes empresas perceberam uma economia de tempo e de custos ao unirem-se a seus principais fornecedores por meio de redes privadas comumente chamadas de eletronic data exchanges (EDI). Esses sistemas automatizam o processo de obtenção, dão suporte ao reabastecimento de estoque automático e aproximam a relação entre os compradores e os principais fornecedores. O sistema exigia grande dispêndio de recursos. Atualmente, com a internet, os custos de implantação vêm caindo significativamente.

Na primeira geração de obtenção informatizada houve o predomínio das comunidades, vitrines e facilitadores de RFP. Na segunda geração houve os distribuidores virtuais e centros de leilão.

Os distribuidores virtuais oferecem compra em um único local para uma fragmentada comunidade de compradores e de vendedores reunindo informações diferentes de produtos a partir de catálogos de vários fornecedores em um megacatálogo.

Os leilões podem ser de dois tipos: direto e reverso.

O leilão direto permite a uma multidão de compradores licitar produtos e serviços de um vendedor individual em uma base competitiva abaixo 
dos preços de mercado. Esses leilões tendem a ser centrados no vendedor. Nesse modelo os preços só se movimentam para cima.

No leilão reverso, os compradores listam os produtos ou serviços que desejam e vendedores pré-qualificados licitam para suprir a necessidade. Os leilões reversos duram até uma determinada hora e o comprador é obrigado a comprar do licitante de menor preço. Os leilões reversos são o oposto do leilão direto, uma vez que os preços se movimentam para baixo. Esses leilões se ajustam a segmentos com alta fragmentação do lado do fornecimento e também são adequados a setores que negociam produtos de um só tipo, não-padronizado e feito sob encomenda.

Na terceira geração haverá os centros de colaboração fazendo mais do que fornecer funcionalidade de transação para as empresas participantes, ajudando-as na administração de ponta a ponta das cadeias de suprimentos.

\section{Evolução dos processos de obtenção eletrônica}

Antes que uma solução de obtenção eletrônica possa ser empregada, uma empresa deve passar por profunda reengenharia do seu processo de obtenção. Automatizar a desordem existente vai apenas piorar a situação. É necessário definir claramente os problemas de negócios que devem ser enfocados por sua solução de obtenção eletrônica.

Compras independentes, processos ineficientes e fontes não-estratégicas são sintomas de uma fragmentação de canal. A compra independente acontece quando os funcionários compram produtos por conta própria debitando na conta da empresa.

A fragmentação também pode ocorrer durante o atendimento do pedido. É raro que todos os produtos sejam entregues na hora certa, e é muito comum se ter pedidos incorretos, parciais ou devolvidos. O cliente deve tentar verificar a situação do pedido com o fornecedor por vários canais offline.

As empresas devem buscar a transição do modelo de negócios "gerenciado pela transação" para o modelo "gerenciado por exceção".

O processo de obtenção de ponta a ponta compõe-se de três fluxos de trabalho: o fluxo de trabalho do pedido, o fluxo de trabalho do atendimento e o fluxo de trabalho do pagamento. No fluxo de trabalho do pedido devemos levar em conta as evoluções tecnológicas ocorridas que podem ir de encontro a regras arcaicas vigentes.

A melhor maneira é proporcionar para o funcionário a opção do autoserviço que permite que as operações comecem e encerrem quando se aciona o botão "comprar". Em aplicações de auto-serviço a capacidade é fundamental. 
Toda solução de e-procurement deve ser projetada para o uso casual de funcionários não-treinados. Caso os funcionários não gostem a aplicação fracassará.

Para que isso ocorra temos que proporcionar acesso seguro, pesquisar catálogos de fornecedores autorizados, criar requisição/pedido, submeter requisição/pedido, exigências de controles de compras e aprovações.

No atendimento, ligações eletrônicas entre sistemas parceiros comerciais de retaguarda expedem entradas de pedidos, atendimentos de pedidos e consultas. O fluxo de trabalho inclui os seguintes passos: despacho do pedido, conectividade com sistemas de contabilidade de retaguarda, conectividade com o fornecedor, rastreamento do pedido, recebimento.

No pagamento, a administração do faturamento é de responsabilidade do patrocinador de mercado que irá criar o fluxo de trabalho.

A principal competência de uma estratégia de obtenção bem-sucedida e eficaz é a aplicação da análise e do planejamento de gastos pelo espectro inteiro das atividades de obtenção. A análise de gastos e o planejamento de obtenção proporcionam ao profissional da área a informação necessária para comprar sabiamente.

O gerenciamento do procurement é fundamental; sem a capacidade de medir, controlar e avaliar continuamente o processo de obtenção, é extremamente difícil medir o desempenho do processo.

A seguir, os passos para se obter uma boa administração do processo.

- Estabelecer metas claras. Automatizar a seleção e compra de bens, cortar custos em toda a organização, informar rapidamente e com precisão os padrões de compra em toda a empresa, eliminar as compras feitas por funcionários não-autorizados.

- Construir uma auditoria de processo. Determinar quais são os fatores que afetam, impedem e interagem com ele. Estabelecer padrões de compra estratégica, transacional e pontual.

- Construir um caso de negócios para a obtenção eletrônica. Desenvolver um caso de negócios de retorno sobre ativos (ROA). A análise de caso de negócios força-o a entender seu contexto.

$$
\mathrm{ROA}=(\text { receitas }- \text { despesas }) / \text { ativos }
$$

- Desenvolver uma matriz de integração do fornecedor. Sem o comprometimento dos fornecedores não haverá integração. É prudente não haver comprometimento de longo prazo. Deve-se fazer uma matriz de integra- 
ção de fornecedor (supplier integration matrix - SIM), classificando-se os fornecedores pelo seu grau de importância:

口 colaborador estratégico - produto incomum, sem igual;

- cooperador estratégico - produto estratégico, mas não único;

- limitado não-estratégico - produtos ou serviços não são estratégicos para o sucesso da organização;

口 conveniência não-estratégica — produtos em abundância no mercado.

- Selecionar uma aplicação eletrônica. Devemos nos precaver contra a propaganda exagerada realizando as perguntas a seguir.

口 Ela dá suporte ao meu processo de obtenção? Essa aplicação alavanca meus outros investimentos de aplicação? Ela trabalhará em harmonia com as outras aplicações? Pode ser estendida?

- Integração é tudo. Focalizando cada uma das áreas de gerenciamento de recurso operacional (operating resource management — ORM), nada será omitido do esforço da integração. Isso vai assegurar que as exigências dos funcionários, fornecedores e compradores serão consideradas quando você estiver construindo sua aplicação de ORM integrada.

- Educar. Qual é o grau de mudança em comportamento que os funcionários, fornecedores e o mercado requerem? O fracasso em cuidar dos obstáculos "suaves" de implementações, ou seja, as pessoas, pode ser a razão mais comum de os projetos não terem sucesso.

\section{Análise do case}

\section{Contexto operacional da instituição objeto do case}

A instituição objeto do case é: Unimed Brasília Cooperativa de Trabalho Médico, pessoa jurídica de direito privado, cooperativa de trabalho sem fins lucrativos, constituída em assembléia geral, em 26 de março de 1978, com sede e foro em Brasília (DF).

A referida instituição vem apresentando déficits operacionais nos últimos exercícios, principalmente pela crescente elevação dos custos da área de saúde, combinada à inadimplência de clientes. No entanto, a Unimed Brasília 
tem envidado esforços na busca de soluções que possam resolver definitivamente as causas primárias do déficit.

Dentro desse escopo está sendo realizada forte restruturação, buscando-se ferramentas para a otimização dos seus processos visando o aumento da receita e a eliminação de desperdícios.

$\mathrm{Na}$ área de materiais e medicamentos, está sendo implantado o SCM, sendo que dentro dessa estratégia o primeiro passo dado foi a utilização do $e$ procurement, na versão do leilão reverso para a qualificação e redução dos preços dos fornecedores.

\section{Alcance da análise de eficiência e eficácia}

Efetuamos a análise com base nos dados proporcionados pelos setores de abastecimento e pela administração geral da Unimed Brasília, de 31 de maio de 2003 a 31 de maio de 2004, elaborados sob a responsabilidade de sua administração.

Nossas análises foram efetuadas de acordo com as técnicas de medição de qualidade própria da atividade na área de saúde, e consistiram, principalmente, na aplicação de procedimentos de revisão de dados coletados na operação normal, assim como pesquisa e entrevistas com o pessoal integrante da instituição.

Os dados coletados foram referentes ao preço, volume, lead time e erros cometidos nos processos na área de abastecimento, compras, logística e áreas de atendimento ao paciente.

\section{Alcance da análise econômico-financeira}

Efetuamos a análise com base nos balancetes patrimoniais da Unimed Brasília, de 31 de maio de 2003 a 31 de maio de 2004 e elaborados sob a responsabilidade de sua administração.

Nossas análises foram efetuadas de acordo com as técnicas de contabilidade gerencial, e consistiram, principalmente, na aplicação de procedimentos de revisão dos dados econômico-financeiros e na averiguação dos critérios adotados na elaboração dos processos junto aos responsáveis pelas áreas de administração e gestão de abastecimento.

\section{Análise dos índices de eficiência e eficácia}

Conforme demonstração no quadro 2, referente ao antes e depois da implementação das técnicas de procurement com ferramental de TI, temos uma vasta quantidade de indicadores que nos informam os resultados da mesma. 
No intuito de simplificar os resultados da implementação do procurement e SCM, resumimos em indicadores de preço, de volume, de tempo, de recursos, de qualidade de informação e serviço.

\section{Volume/preço}

Percebe-se uma importante redução do preço por quantidade de material, apesar de os medicamentos terem sofrido fortes incrementos nos preços no período estudado, acima de $30 \%$, de forma que o resultado desta análise não demonstra realmente a melhora na eficiência já que sofre uma deficiência ao não contemplar as correções monetárias e influências do mercado cambial.

Assim podemos ver que a implementação dos novos sistemas agregaram valor aos processos, diminuindo a relação volume/preço e no caso pontual dos medicamentos, minimizando o efeito do forte aumento dos preços (quadro 2).

\section{Tempo/recursos}

Esses foram os indicadores que revelam o altíssimo valor agregado na implementação do sistema, a redução foi mais do que significativa nos tempos do processo de compra e abastecimento: de 15 para dois dias, uma redução de 86,7\%. Com a diminuição dos recursos de mão-de-obra de cinco para duas pessoas.

\section{Qualidade da informação}

Observamos uma forte diminuição dos erros totais em quantidade, mas observa-se um aumento de erros de informação dos totais. Dessa maneira demonstramos as debilidades e inconvenientes que a mudança e implementação de um novo sistema têm, sendo este um dos riscos na implementação desse tipo de sistema.

\section{Qualidade do serviço}

No setor de compras observamos um elevado nível de eficiência em questões de tempo de resposta interno e fechamento de operações, mas em relação a qualidade e tempo de resposta externo (dos fornecedores), observamos a dificuldade num princípio de coordenação e implementação dos novos modelos

RAP Rio de Janeiro 40(4):699-729, Jul./Ago. 2006 
de logística com os fornecedores. Como o risco citado anteriormente, este deve ser levado em conta no planejamento, mas à frente nos pontos de riscos.

No setor de atendimento médico, observou-se uma forte diminuição de tempo de espera do paciente, motivada pela flexibilização e ágil resposta entre o setor de abastecimento e compras e setores usuários, com maiores e melhores controles internos. Essa melhora foi percebida pelos clientes, agregando valor.

\section{Análise dos ratios econômico-financeiros}

\section{Demonstrações contábeis}

- Aumento do ativo, motivado principalmente em participações na confederação.

- Aumento de passivos em longo prazo, destino: financiamento de investimentos. Aumento de participações na confederação.

- Diminuição dos estoques. Possivelmente os números não demonstrem o real impacto na eficiência como a diminuição do $50 \%$ no prazo médio de estoques, motivada pelo forte incremento nos preços dos medicamentos e demais materiais. Observa-se uma diminuição dos estoques.

- Aumento dos passivos circulantes motivado pelo aumento de câmara de compensação com a confederação Unimed e Unimeds a pagar, em 49\%.

- Diminuição das vendas em $43 \%$ em função do encerramento dos contratos coletivos.

- Diminuição das despesas operacionais na mesma proporção que as vendas, porém há resultado negativo (perda) no período.

- Aumento da perda líquida do exercício decorrente da diminuição na venda de contratos coletivos.

- Diminuição das despesas operativas na mesma proporção que as vendas, porém com resultado negativo (perda) no período.

\section{Índices econômicos e de rentabilidade}

Política de estocagem: diminuição em 50\% no tempo médio dos estoques, de 121 para 62 dias. 
Rentabilidade operativa do ativo (ROA) e demais indicadores de rentabilidade: são negativos, pois o denominador na fórmula para o cálculo é negativo, é o déficit do período.

\section{Índices de liquidez e financiamento}

No curto prazo, observamos que a relação entre ativos e passivos circulantes passou de $86 \%$ para $88 \%$. Esse índice, apesar do leve aumento, continua abaixo do desejado. Mas é próprio desse tipo de atividade ter uma relação menor que um.

Na análise dos ativos e passivos totais, a instituição encontra-se numa posição mais confortável, demonstrando também uma melhoria na liquidez de 1,04 a 1,11 .

\section{Análise de riscos}

Os riscos envolvidos e considerados neste case podem ser dos seguintes tipos: macro, econômico-financeiros e operacionais.

Toda mudança num sistema significa origem e necessidade de investimento, de despesas, objetivando um lucro que pode ser obtido com a redução de custos e despesas. Assim, podemos afirmar que a implementação do sistema é um projeto. Para poder avaliar e tomar decisões sobre sua implementação ou não, todo projeto é aberto financeiramente num fluxo de caixa projetado e descontado a uma taxa de desconto.

Uma das maneiras mais adequadas para determinação da taxa de desconto é o método de custo promédio ponderado do capital (WACC), uma média ponderada dos custos de capital próprio e de terceiros, onde calculamos o valor presente líquido (VPL), taxa interna de retorno (TIR), payback discount (período de recuperação do investimento) para a tomada de decisões.

Todo projeto é influenciado por riscos dos tipos macro, econômico-financeiros e operacionais. Há riscos que podem ser fortemente minimizados, mas outros, de caráter sistêmico, não podem ser eliminados.

Neste case os riscos macro e financeiros foram fortemente minimizados pela utilização de hedge cambial, juros e considerações de risco-país no pior dos cenários publicados pelo Bacen e conforme pesquisas realizadas pelos maiores analistas financeiros do Brasil.

A implementação do sistema possui uma inumerável quantidade de riscos, e a maior parte vincula-se à segurança do sistema aplicativo, precisão dos sistemas, queda dos sistemas e continuidade do serviço, disponibilidade dos sistemas, assim como o risco cultural (Ernest \& Young - Consulting). 
Riscos relacionados a sistemas são fortemente diminuídos e minimizados com a aquisição de um produto conhecido, provado, de rápida implantação, com grande apoio técnico. É aqui onde o trabalho de procurement e benchmarking tem um peso importante.

Risco cultural está vinculado à cultura, usos e costumes de comercialização de bens e serviços no país, na responsabilidade e qualidade na venda de bens e serviços, e ainda mais pontualmente no cumprimento dos tempos de resposta e respeito na qualidade dos produtos pautados. Sem dúvida, esse foi um ponto de extrema importância nos primeiros momentos da implementação, já que causou uma demora importante na entrega de alguns medicamentos e materiais (quadro 2), assim como a entrega de medicamentos de diferente qualidade, originando elevadíssimos custos para a instituição, que teve de manter os estoques de segurança levemente elevados até selecionar os fornecedores previamente classificados.

\section{Inconvenientes originados na implementação}

A maior complexidade e inconveniente que surgiu na implementação do case foi: parametrização dos fornecedores, registro dos fornecedores, logística de entrega, entrega de itens errados pelos fornecedores.

Dentro do risco temos a aceitação por parte do quadro do pessoal, que é muito importante, pela possível necessidade de reorganizar pessoal e incorporar novos empregados. Nesse ponto, observou-se uma ótima aceitação por parte do pessoal e não foi necessário gastar tempo e dinheiro em reorganização. Em conclusão o resumo da análise de implementação do case de procurement, nos serve de base para o desenvolvimento desta análise, onde foi projetada a implementação da supply chain tech total na Unimed Brasília com dificuldades inerentes à implementação do sistema, mas com resultados positivos para a empresa, sendo agora o próximo passo a implementação das ferramentas de TI que interligarão os principais fornecedores escolhidos para a realização de mais um passo na utilização plena do SCM.

\section{Conclusão}

Vivemos hoje a era da globalização. Com isso estamos observando a padronização dos conceitos e tendências que, discretamente adaptados aos regionalismos, permitem que obtenhamos uma grande redução nos custos de produção e manutenção dos produtos e serviços.

Falamos muito em diferenciação, mas o que realmente queremos dizer com isso? Todas as empresas buscam a tal da "diferenciação", seja no 
atendimento customizado ou na adequação do produto à necessidade do cliente. Temos que surpreendê-los incessantemente. Com a difusão desse conceito, observamos uma padronização de comportamentos que estabelecem um novo paradigma. Essa nova condição é incorporada ao produto ou serviço que deixará de ser novidade, tornando-se mais uma característica da linha basal de produção a ser alcançada para se estabelecer no mercado.

Com esse novo padrão de qualidade percebemos que a competição já não é mais baseada na empresa isolada, mas sim na sua cadeia de valor, onde dentro dela destacamos a cadeia de suprimentos.

Ao utilizar os sistemas de informática integrados para mapear as vontades e necessidades dos clientes, com as várias versões de CRM/EDI/ERP (customer relationship management/electronic data interchange/enterprise resource planning) disponíveis no mercado, temos a possibilidade de conhecer melhor nosso cliente, e com isso adaptar o nosso SCM às suas necessidades. Analisar as tendências do mercado com a utilização de métodos de avaliação estratégica para conhecermos nossos pontos fortes e fracos, além da consciência do tamanho que queremos ter, são pontos importantes para desenvolvermos um plano logístico eficaz na colocação de novos produtos no mercado.

O padrão de desenvolvimento dos produtos evoluiu muito nas últimas décadas. O produto torna-se commodities e são utilizados kaizen e TQC na sua produção tendo boa qualidade, durabilidade e assistência técnica. O nível de conscientização mudou e qualquer chance de problema é rapidamente corrigido com a realização de um recall.

Não podemos ficar presos às formas antigas de avaliação do mercado. O sucesso passado não garante o sucesso futuro e as adaptações decorrentes da evolução tecnológica sempre trazem conflitos éticos que, com o tempo, tendem a ser naturalmente resolvidos.

Nesse contexto as grandes ferramentas de mudança e adaptação são os sistemas de informação.

Sim, a cadeia de suprimentos integrada é o novo foco de concorrência.

\section{Referências bibliográficas}

ANUPINDI, R. et al. Managing business process flows. New Jersey: Prentice Hall, 1999.

ARAVECHIA, Carlos H. M.; PIRES, Sílvio R. I. Gestão de cadeia de suprimentos e avaliação de desempenho. In: ENANPAD (Encontro Nacional de Programas de Pós-Graduação em Administração), 23., Florianópolis. Anais. Florianópolis: UFSC, 2000.

RAP Rio de Janeiro 40(4):699-729, Jul./Ago. 2006 
BAKER, M. J. Dictionary of marketing and advertising. 2. ed. New York: Nichols Publishing, 1990.

BAKOS, Y.; BRYNJOLFSSON, E. Organizational partnerships and the virtual corporation. In: BAKOS, Y. Information technology and industrial competitiveness: how information technology shapes competition. Kluwer Academic Publishers, 1997.

BALLOU, R. H. Logística empresarial. São Paulo: Atlas, 1993.

Gerenciamento da cadeia de suprimentos: planejamento, organização e logística empresarial. 4. ed. Porto Alegre: Bookman, 2001.

BEAMON, Benita M. Measuring supply chain performance. International Journal of Operations \& Production Management, v. 19, n. 3, p. 275-292, 1999.

BOWERSOX, D. J.; CLOSS, D. J. Logistical management: the integrated supply chain process. Singapore: McGraw-Hill, 1996.

et al. Logistical excellence: it's not business as usual. Burlington, MA: Digital Equipment Press, 1992.

BREWER, Peter C.; SPEH, Thomas W. Adapting the balanced scorecard to supply chain management. Supply Chain Management Review, v. 5, n. 2, p. 48-56, Mar./Apr. 2001.

CHOPRA, S.; MEINDL, P. Supply chain management: strategy, planning, and operation. New Jersey: Prentice Hall, 2001.

CHRISTOPHER, M. Logística e gerenciamento da cadeia de suprimentos - estratégias para a redução de custos e melhoria de serviços. São Paulo: Pioneira, 1999.

CLAVER, E.; GONZALEZ, R.; LLOPIS, J. An analysis of research in information systems (1981-1997). Information \& Management, v. 37, n. 4, p. 181-195, Apr. 2000.

CLM (COUNCIL OF LOGISTICS MANAGEMENT). Article 1. Disponível em: <www.clm1.org.br/> . Acesso em: 8 abr. 2003

CRAVENS, Karen; PIERCY, Nigel: CRAVENS, David. Assessing the performance of strategic alliances: matching metrics to strategies. European Management Journal, v. 18, n. 5, p. 529-541, Oct. 2000.

DAMODARAN, A. Avaliação de investimentos. Rio de Janeiro: Qualitymark, 1997.

DAVIS, T. Effective supply chain management. Sloan Management Review, Summer 1993.

DREYER, Dennis E. Performance measurement: a practitioner's perspective. Supply Chain Management Review, v. 4, n. 4, p. 63-68, Sept./Oct. 2000. 
FLEURY, P. F. Supply chain management: conceitos, oportunidades e desafios de implementação. Tecnologística, n. 39, fev. 1999.

; WANKE, P.; FIGUEIREDO, K. Logística empresarial: a perspectiva brasileira. São Paulo: Atlas, 2000.

GASPARETO, V. Proposta de uma sistemática para avaliação de desempenho em cadeias de suprimento. 2003. Tese (Mestrado em Engenharia de Produção) — Universidade Federal de Santa Catarina.

GUNASEKARAN, A.; PATEL, C.; TIRTIROGLU, E. Performance measures and metrics in a supply chain environment. International Journal of Operations \& Production Management, v. 21 , n. $1 / 2$, p. $71-87,2001$.

HAX A. C.; GOLOVIN J. Hierarchical production planning systems. Studies on Operations Management, 1978.

HOLMBERG, Stefan. A systems perspective on supply chain measurements. International Journal of Physical Distribution \& Logistics Management, v. 30, n. 10, p. 847-868, 2000.

LAMBERT, D. M. Strategic logistics management. Homewood: R. D. Irwin, 1993.

.; POHLEN, Terrance L. Supply chain metrics. The International Journal of Logistics Management, v. 12, n. 1, p. 1-19, 2001.

LAMBERT, R.; COOPER, M.; PAGH, C. Supply chain management: implementation issues and research opportunities. The International Journal of Logistics Management, v. 9, n. 2, 1998.

MCKINSEY \& COMPANY INC.; COPELAND, T.; KOLLER, T.; MURRIN, J. Valuation. São Paulo: Pearson, 2002.

MIRANDA, Núvia G. Martes de; CORRÊA, Henrique Luiz. Uma análise parcial da rede de suprimentos da indústria automobilística brasileira. Revista de Administração, São Paulo, v. 31, n. 1, p. 5-13, jan./fev. 1996.

NAZÁRIO, P. A importância de sistemas de informação para a competitividade logística. Rio de Janeiro: Centro de Estudos em Logística, Coppead, 1999.

NARASIMHAN, Ram; KIM, Soo Wook. Effect of supply chain metrics integration on the relationship between diversification and performance: evidence from Japanese and Korean firms. Journal of Operations Management, n. 20, p. 303-323, 2002.

OLINQUEVITCH, J. L.; SANTI FILHO, A. de. Análise de balanço para controle gerencial. São Paulo: Atlas, 2004.

PIRES, Márcio de Souza. Construção do modelo endógeno, sistêmico e distintivo de desenvolvimento regional e a sua validação através da elaboração e da aplicação de uma metodologia ao caso do Mercoeste. 2001. Tese (Doutorado em Engenharia de Produção) — Programa de 
Pós-Graduação em Engenharia de Produção, Universidade Federal de Santa Catarina, Florianópolis.

PORTER, Michael E. Estratégia competitiva: técnicas para análise de indústrias e da concorrência. 5. ed. Rio de Janeiro: Campus, 1991.

OSTER, S. M. Modern competitive analysis. New York: Oxford University Press, 1999.

RAVI, K.; MARCIA, R. E-business roadmap for success. New York: Addison-Wesley, 1999.

SANTOS, R. A. B. CPFR - planejamento colaborativo: em busca da redução de custos e aumento do nível de serviço nas cadeias de suprimento. Tecnologística, v. 60, p. 60-66, 2 nov. 2000.

SCC (SUPPLY CHAIN COUNCIL). Supply-chain operations reference-model. Release 5.0. SCC: Pittsburgh, 2002

SIMCHI-LEVI, D.; KAMINSKY, P.; SIMCHI-LEVI, E. Designing and managing the supply chain. McGraw-Hill, 2000.

STANK, Theodore et al. Supply chain integration: tales from the trenches. Supply Chain Management Review, p. 62-69, May/June 2001.

STEWART, Gordon. Supply chain performance benchmarking study reveals keys to supply chain excellence. Logistics Information Management, v. 8, n. 2, p. 38-44, 1995.

STRATI, A. Aesthetics and organization without walls. Studies in Culture, Organization and Societies, p. 83-105, 1995.

TURBAN; MCLEAN; WETHERBE. Tecnologia da informação para a gestão. 3. ed. Artmed, 2004.

VERGARA, Sylvia Constant. Projetos e relatórios de pesquisa em administração. 2. ed. São Paulo: Atlas, 1998.

YIN, R. Case study research: design and methods. Newbury Park: Sage, 1991.

WANKE, Peter. Uma revisão dos programas de resposta rápida: ECR, CRP, VMI, CPFR, JIT II. Disponível em: <www.centrodelogistica.2004.com.br/new/fs-public.htm>. Acesso em: 31 jul. 2006. 